\title{
Pleomorphic Rhabdomyosarcoma of the Uterus - Case Report and a Systematic Review of the Literature
}

\author{
SARA ALAVI ${ }^{1}$, LENA ECKES ${ }^{1}$, ROBERT KRATSCHELL $^{1}$, ELIANE TABEA TAUBE ${ }^{2}$, \\ FRIEDERIKE ROSSECK ${ }^{2}$, GERO WIENERS ${ }^{3}$ and JALID SEHOULI ${ }^{1}$ \\ Departments of ${ }^{1}$ Gynecology with Center for Oncological Surgery, \\ European Competence Center for Ovarian Cancer, ${ }^{2}$ Pathology and ${ }^{3}$ Radiology, \\ Charité - Campus Virchow-Klinikum, University Medicine of Berlin, Berlin, Germany
}

\begin{abstract}
Background: Pleomorphic rhabdomyosarcomas of the uterus, mainly occurring in postmenopausal women with leading symptoms of vaginal bleeding and abdominal pain, are very rare malignant tumors of the female genital tract. Due to the inefficiency of the adjuvant therapy, the outcome remains poor in the majority of the reported cases. Patient and Methods: We present a case of a 73-year-old patient diagnosed with pleomorphic rhabdomyosarcoma of the uterus. Together with the case report, a systematic review of the literature is presented focusing on different treatment strategies and their outcome. The $95 \%$ confidence interval (CI) of the overall mean survival and the respective mean survival of each different treatment strategy was calculated using SAS Studio. Results: In the presented case, the patient showed no symptoms and was admitted into hospital due to abnormal uterine findings during a routine gynecological examination. Vaginal ultrasound scans showed a severely enlarged and intracavitaryly filled uterus. The patient underwent hysterectomy, as well as bilateral salpingo-oophorectomy. Regarding the systematic review of the literature, patients with adjuvant chemotherapy show the best outcome with a mean survival rate of $15.8 \pm 7.3$ months (one patient excluded), whereas with a mean survival rate of $4.1 \pm 5.2$ months, patients with sole surgical treatment show the shortest survival after diagnosis. Conclusion: Although there is no standardized approach in the treatment of this rare disease, we present a differentiated overview.
\end{abstract}

Correspondence to: Prof. Dr. med. Jalid Sehouli, Department of Gynecology and Obstetrics, Charité - Campus Virchow-Klinikum, University Medicine of Berlin, Augustenburger Platz 1, 13353 Berlin, Germany. Tel: +49 30450564002, Fax: +49 30450564910, e-mail: jalid.sehouli@charite.de

Key Words: Rhabdomyosarcoma, pleomorphic, uterus.
With an estimated incidence of less than $0.5 / 100,000$, pleomorphic rhabdomyosarcoma of the uterus is a very rare and poorly investigated disease $(1,2)$. Mainly occurring in postmenopausal women, the leading symptoms are vaginal bleeding and abdominal pain (1-14). Due to the high malignancy of the tumor and the inefficiency of the adjuvant therapy, the outcome remains poor in the majority of the reported cases (1-14).

\section{Materials and Methods}

A review of the English-language literature since 1980 for "pleomorphic rhabdomyosarcoma of the uterus" was performed. Depending on the treatment received, the cases were organized in different groups (Tables I and II). The 95\% confidence interval (CI) of the overall mean survival and the respective mean survival of each treatment group was calculated using SAS Studio (https://www.sas.com/en_us/software/foundation/studio.html).

\section{Results}

Case Report. A 73-year-old patient was admitted to the hospital due to abnormal uterine findings during a routine gynecological examination. The patient's medical history included breast cancer with breast-conserving surgical treatment followed by irradiation and tamoxifen therapy over a period of three years, as well as a total thyroidectomy.

A hysteroscopy, dilatation and curettage of the uterus were performed. The histopathological results showed a poorly differentiated (G3) pleomorphic rhabdomyosarcoma of the uterus with a weak expression of progesterone receptor and negative expression of estrogen receptor.

The patient was then referred to our hospital for a second opinion and further treatment. Pelvic examination and vaginal ultrasound scan showed a severely enlarged and intracavitaryly filled uterus. In the interview, the patient reported no symptoms, especially no vaginal bleeding or abdominal pains. A subsequent computerized tomography (CT) of the pelvis revealed an inhomogeneous contrast- 
Table I. Literature overview with particular emphasis on adjuvant treatment.

\begin{tabular}{|c|c|c|c|c|}
\hline Series & Age & $\begin{array}{c}\text { Extrauterine } \\
\text { spread }\end{array}$ & Treatment & Outcome \\
\hline \multicolumn{5}{|l|}{ Surgical treatment } \\
\hline Ordi et al., 1997 (6) & 87 & Yes & HE & DOD, 1 month \\
\hline Mccluggage et al., 2002 (4) & 67 & Yes & Tumordebulking, BSO & DOD, 0.1 month \\
\hline Fadare et al., 2010 (5) & 51 & Yes & HE, BSO, LNE, OE & DOD, 0.5 month \\
\hline Fadare et al., 2010 (5) & 74 & Yes & HE, BSO, LNE, OE & Loss of FU \\
\hline Leung et al., 2009 (8) & 68 & No & $\mathrm{HE}, \mathrm{BSO}$ & NED, 12 months \\
\hline Jaworski et al., 1984 (14) & 71 & No & HE, BSO & NED, 7 months \\
\hline \multicolumn{5}{|l|}{$\begin{array}{l}\text { Surgical treatment with } \\
\text { adjuvant pelvic radiation }\end{array}$} \\
\hline Ferguson et al., 2007 (9) & 69 & Yes & $\mathrm{HE}, \mathrm{BSO}+\mathrm{PR}$ & DOD, 5 months \\
\hline Fadare et al., 2010 (5) & 79 & Yes & HE, BSO, LNE, OE + PR & DOD, 6.3 months \\
\hline Siegal et al., 1983 (10) & 69 & No & HE, LNE + PR & NED, 3 months \\
\hline Holcomb et al.1999 (2) & 63 & No & $\mathrm{HE}, \mathrm{BSO}+\mathrm{PR}$ & DOD, 24 months \\
\hline Podczaski et al. 1990 (12) & 73 & No & HE, LS, BO, LNE, OE + PR & DOD, 3 months \\
\hline Present case & 73 & No & $\mathrm{HE}, \mathrm{BSO}+\mathrm{PR}$ & NED, 3 months \\
\hline \multicolumn{5}{|l|}{$\begin{array}{l}\text { Surgical treatment with } \\
\text { adjuvant chemotherapy }\end{array}$} \\
\hline Vakiani et al., 1982 (11) & 68 & Yes & $\mathrm{HE}, \mathrm{BSO}+\mathrm{ChT}(\mathrm{AM}, \mathrm{AD}, \mathrm{VI}, \mathrm{CY})$ & DOD, 14 months \\
\hline Ordi et al., 1997 (6) & 67 & Yes & $\mathrm{HE}+\mathrm{ChT}(\mathrm{VI}, \mathrm{AD}, \mathrm{CY})$ & DOD, 15 months \\
\hline Ordi et al., 1997 (6) & 60 & Yes & $\mathrm{HE}+\mathrm{ChT}(\mathrm{CIs}, \mathrm{DO})$ & DOD, 72 months (probably of OD) \\
\hline Borka et al., 2006 (3) & 67 & Yes & $\mathrm{HE}, \mathrm{BSO}, \mathrm{LNE}, \mathrm{pCE}+\mathrm{ChT}(\mathrm{DO})$ & NED, 12 months \\
\hline Ordi et al., 1997 (6) & 35 & No & $\mathrm{HE}+\mathrm{ChT}$ & DOD, 15 months \\
\hline Ordi et al., 1997 (6) & 80 & No & $\mathrm{HE}+\mathrm{ChT}(\mathrm{VI}, \mathrm{AD})$ & DOD, 9 months \\
\hline Chmaj-Wierzchowska et al., 2010 (1) & 66 & No & $\mathrm{HE}, \mathrm{BSO}+\mathrm{ChT}(\mathrm{CY}, \mathrm{VI}, \mathrm{DO}, \mathrm{DA})$ & DOD, 30 months \\
\hline \multicolumn{5}{|l|}{$\begin{array}{l}\text { Surgical treatment with adjuvant } \\
\text { chemotherapy and pelvic radiation }\end{array}$} \\
\hline Ordi et al., 1997 (6) & 61 & Yes & $\mathrm{HE}+\mathrm{ChT}(\mathrm{DO}, \mathrm{DA}, \mathrm{CIs})+\mathrm{PR}$ & DOD, 15 months \\
\hline Okada et al., 1999 (13) & 53 & Yes & $\mathrm{HE}, \mathrm{BSO}, \mathrm{LNE}+\mathrm{ChT}(5-\mathrm{FU})+\mathrm{PR}$ & $\mathrm{RD}, 2$ months \\
\hline Yeasmin et al., 2008 (7) & 60 & Yes & $\mathrm{HE}, \mathrm{BSO}, \mathrm{LNE}, \mathrm{OE}+\mathrm{ChT}+\mathrm{PR}$ & DOD, 20 months \\
\hline Fadare et al., 2010 (5) & 68 & Yes & $\mathrm{HE}, \mathrm{BSO}, \mathrm{LNE}, \mathrm{OE}+\mathrm{ChT}(\mathrm{VI}, \mathrm{AD}, \mathrm{CY})+\mathrm{PR}$ & DOD, 19 months \\
\hline Ordi et al., 1997 (6) & 69 & No & $\mathrm{HE}+\mathrm{ChT}+\mathrm{PR}$ & DOD, 6 months \\
\hline
\end{tabular}

AD, Actinomycin D; AM, adiramycin; BSO, bilateral salpingo-oophorectomy; ChT, chemotherapy; CIs, cisplatin; CY, cyclophosphamide; DA, dacarbazine; DO, doxorubicine; DOD, death of disease; FU, follow-up; HE, hysterectomy; LNE, lymphonodectomy; NED, no evidence of disease; $\mathrm{OD}$, other disease; OE, omentectomy; PR, pelvic radiation; $\mathrm{pCE}$, partial colectomy; VI, vincristine.

enhancing tumor of the corpus uteri with invasion of the cervix uteri, adjacent to bladder and rectum (Figure 1). While an infiltration of the rectum could not be safely excluded, the CT scan showed no involvement of other organs or lymph nodes. Except an elevated lactate dehydrogenase (LDH) level of $264 \mathrm{U} / 1$, all other blood counts were without pathological findings.

An inferior medium laparotomy, hysterectomy, as well as bilateral salpingo-oophorectomy, were performed. Intraoperatively, the peritoneum was smooth and no signs of further tumor spread could be detected.

The case was discussed in our interdisciplinary online tumor conference (15). Due to the lack of evidence-based profit of adjuvant chemotherapy, a recommendation for pelvic radiation was made. The patient rejected any further treatment and shows currently no evidence of disease.

Pathology findings. Macroscopically, the tumor $(65 \times 60 \times 50$ $\mathrm{mm}$ ) was whitish-/yellowish-colored and showed, in some parts, an infiltration of the myometrium, while an intracavitary location as a polypoid lesion in other parts (Figure 2).

Microscopical findings were a mesenchymal tumor containing spindle-shaped, partly interlaced, partly polygonal and size-variable cells with an eosinophilic, in some extend fibrillic, cytoplasm and pleomorphic nuclei, often with prominent nucleoli (Figure 3B). Furthermore, polynuclear cells and cells with bizarrely enlarged nuclei could be detected (Figure 3A). 
Table II. Summary and patient's characteristics of the literature overview.

\begin{tabular}{|c|c|}
\hline Characteristics & Value \\
\hline Total number of patients & $\mathrm{n}=24(100 \%)$ \\
\hline Median age in years & $66.6 \pm 10.4$ \\
\hline Extrauterine spread at diagnosis [yes/no] & $14(58 \%) / 10(42 \%)$ \\
\hline Overall mean survival after diagnosis in months & $12.8 \pm 15.2(\mathrm{CI}=6.2-19.6)$ \\
\hline Mean survival without extrauterine spread in months & $11.2 \pm 11.1(\mathrm{CI}=4.5-17.9)$ \\
\hline Mean survival with extrauterine spread in months & $14.0 \pm 15.8(\mathrm{CI}=2.6-25.4)$ \\
\hline Patients with sole surgical treatment & $\mathrm{n}=6(25 \%)$ \\
\hline Extrauterine spread at diagnosis [yes/no] & $4 / 2$ \\
\hline Mean survival after diagnosis in months & $4.1 \pm 5.2(\mathrm{CI}=-2.4-10.6)$ \\
\hline Patients with surgical treatment and adjuvant pelvic radiation & $\mathrm{n}=6(25 \%)$ \\
\hline Extrauterine spread at diagnosis [yes/no] & $2 / 4$ \\
\hline Mean survival after diagnosis in months & $7.4 \pm 8.3(\mathrm{CI}=-1.3-16)$ \\
\hline Patients with surgical treatment and adjuvant chemotherapy & $\mathrm{n}=7(29 \%)$ \\
\hline Extrauterine spread at diagnosis [yes/no] & $4 / 3$ \\
\hline Mean survival after diagnosis in months & $23.9 \pm 22.3(\mathrm{CI}=3.3-44.4)$ \\
\hline (One patient excluded) & $(15.8 \pm 7.3)$ \\
\hline Patients with surgical treatment and adjuvant pelvic radiation and chemotherapy & $\mathrm{n}=5(21 \%)$ \\
\hline Extrauterine spread at diagnosis [yes/no] & $4 / 1$ \\
\hline Mean survival after diagnosis in months & $12.4 \pm 8(\mathrm{CI}=2.4-22.6)$ \\
\hline
\end{tabular}

\section{CI, Confidence interval.}
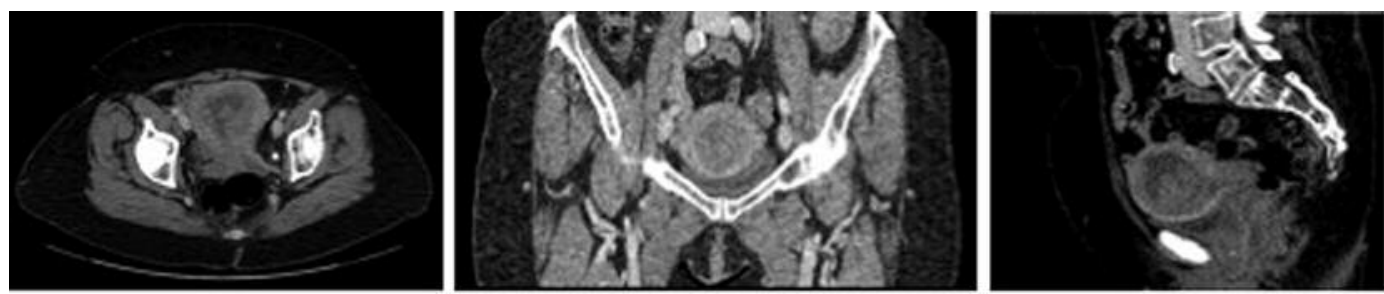

Figure 1. Computed tomography images revealing an inhomogeneous contrast-enhancing tumor of the corpus uteri with invasion of the cervix uteri, adjacent to bladder and rectum.

MyoD1 (Dako-Agilent Pathology Solution, Santa Clara, CA, USA) shows moderate cytoplasmic staining in morphologically-appearing rhabdomyoblasts (Figure 4A). Desmin (Dako-Agilent Pathology Solution) (Figure 4B) and CD10 (Leica Biosystems, Nussloch, Germany) were partly positive. Ki-67 (Dako-Agilent Pathology Solution) was approximately $70 \%$. An epithelial component was not detectable, either with conventional histomorphology or with immunohistochemistry for pan cytokeratin (Dako-Agilent Pathology Solution) (Figure 4C).

In conclusion, the presented case shows the typical features described for rhabdomyosarcoma: the polypoid or invasive expansion macroscopically, histologically identifiable rhabdomyoblasts and the background of sarcomatoid-looking cells of round, polygonal or spindle-shaped morphology (6). Immunohistochemically, the mesenchymal origin of the
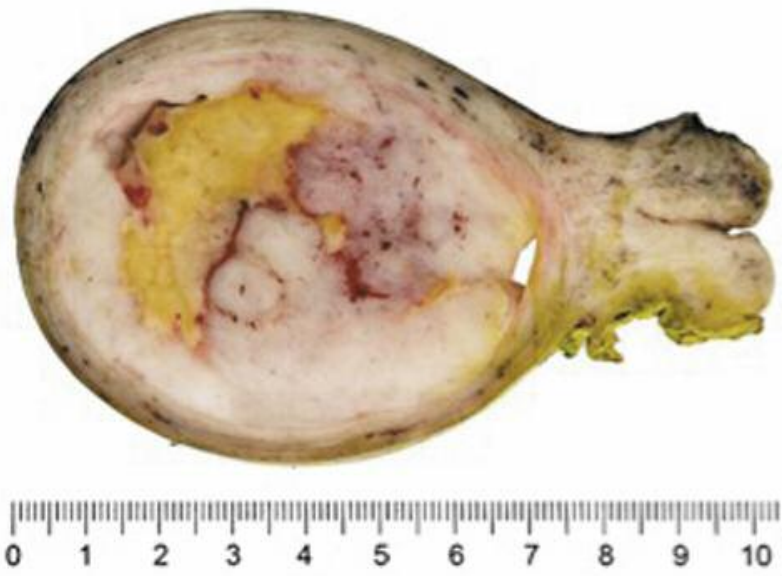

Figure 2. Macroscopic appearance of rhabdomyosarcoma. 

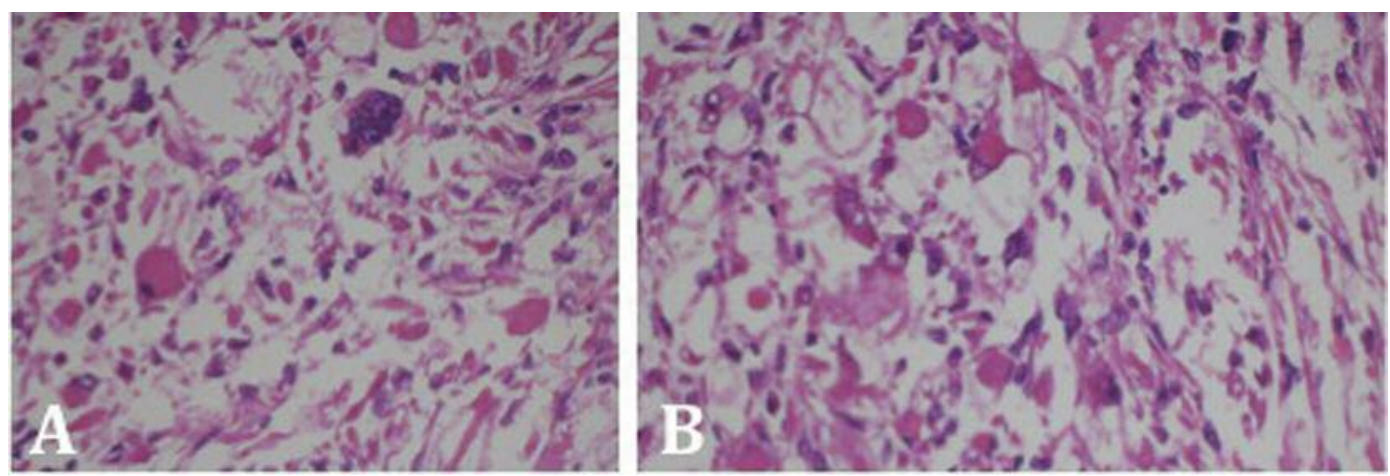

Figure 3. A. Sarcoma with intermingeld bizarre enlarged and multinucleated nuclei. B. Histological detection of rhabdomyoblasts.
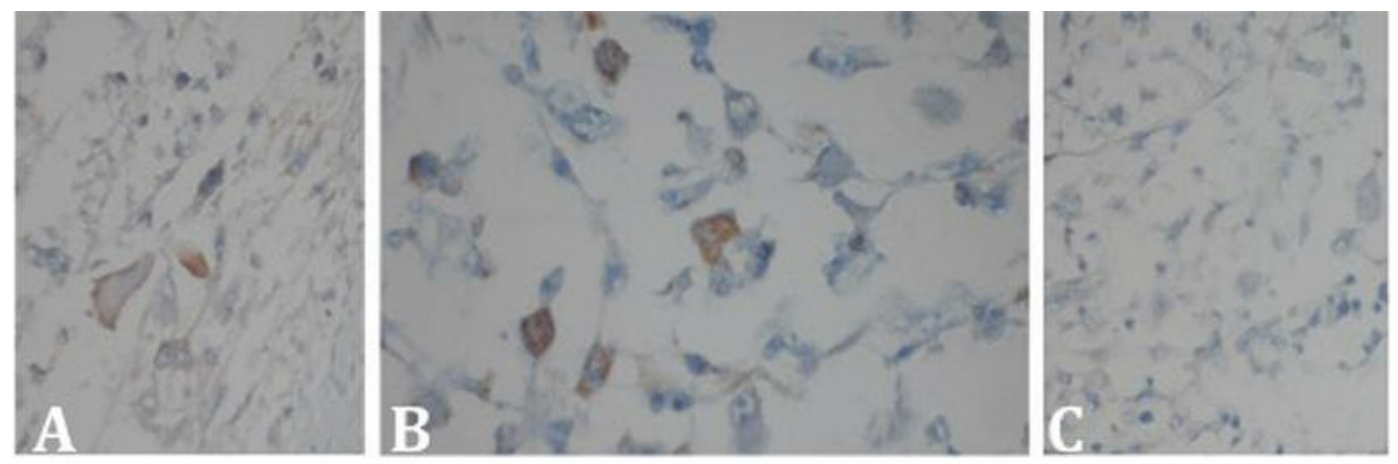

Figure 4. A. Moderate cytoplasmic staining for MyoD1 in morphological rhabdomyoblasts. B. Some desmin-positive cells are detected. C. Immunohistochemistry for pan cytokeratin is negative.

neoplastic cells is shown (6). In the presented case, the immunohistochemical myogenic marker shows only moderate cytoplasmic staining for MyoD1 and partial desmin positivity.

\section{Discussion}

We present the case of a 73-year-old woman with pleomorphic rhabdomyosarcoma of the uterus with no symptoms and an elevated LDH level at initial examination and complete remission following surgery.

Pleomorphic rhabdomyosarcoma of the uterus is a rare disease. More frequent sarcomas of the uterus are leiomyosarcomas, stromal sarcomas and undifferentiated sarcomas (4). Frequently, like in the presented case, overlaps of rhabdomyosarcoma and undifferentiated sarcoma exist. This might be due to a dedifferentiation process of the rhabdomyosarcoma associated with subsequent loss of the immunohistochemical myogenic markers.

Between 1982 and 2015, twenty-four cases of pleomorphic rhabdomyosarcoma of the uterus have been described in the
English-language literature, including the present case (1-14). The median age of the patients was $66.6 \pm 10.4$ years with a range between 35 and 87 years. Fourteen $(58 \%)$ out of all twenty-four patients presented with extrauterine spread at the time of diagnosis. While the overall mean survival rate was $12.8 \pm 15.2$ months $(\mathrm{CI}=6.2-19.6)$, the mean survival rate of patients without extrauterine spread at the time of diagnosis was $11.2 \pm 11.1$ months $(\mathrm{CI}=4.5-17.9)$ and the mean survival rate of patients with extrauterine spread at the time of diagnosis was $14.0 \pm 15.8$ months $(\mathrm{CI}=2.6-25.4)$. Seventeen patients $(71 \%)$ died due to consequences of the disease, eight (33\%) of them within the first year. Regarding the surgical treatment in all cases $(100 \%)$, a hysterectomy was performed. Additionally, fifteen $(63 \%)$ patients underwent bilateral salpingo-oophorectomy, nine (38\%) patients lymphonodectomy and six (25\%) patients either partial or complete omentectomy.

Sole surgical treatment was carried-out in six patients $(25 \%)$. From this patient collective, three out of four patients with extrauterine spread at the time of diagnosis died within 
the first month and one refused further follow-up. While the mean survival rate was 4.1 \pm 5.2 months $(\mathrm{CI}=-2.4-10.6)$, the two patients with no initial spread showed no evidence of disease seven and twelve month after diagnosis. Further six patients $(25 \%)$ received adjuvant pelvic radiation after surgical tumor resection. Two out of this patient collective presented with extrauterine spread; for the other four patients, the disease was limited to the uterus. The mean survival rate was $7.4 \pm 8.3$ months $(\mathrm{CI}=-1.3-16)$ after diagnosis. In seven patients (29\%), surgical treatment and adjuvant chemotherapy was performed, with four of them initially presenting with extrauterine spread. The mean survival rate was $23.9 \pm 22.3$ months (CI=3.3-44.4). The survival rate of one patient, being 72 months after diagnosis, seems to fall out of the series. This value was excluded as the median survival rate was $15.8 \pm 7.3$ months. The final group of five patients $(21 \%)$ received adjuvant pelvic radiation, as well as chemotherapy. Four of these five patients presented with extrauterine spread at the time of diagnosis. The mean survival rate was $12 \pm 8(\mathrm{CI}=2.4-$ 22.6) months.

In consideration of the small number of patients, one can see a slight tendency towards surgical treatment with adjuvant pelvic radiation in patients with initially limited disease, while surgical treatment with adjuvant pelvic radiation, as well as chemotherapy, was mainly the management of patients with extrauterine spread at the time of diagnosis. Patients with adjuvant chemotherapy showed the best outcome with a mean survival rate of $15.8 \pm 7.3$ months (one patient excluded), whereas, with a mean survival rate of $4.1 \pm 5.2$ months, patients with sole surgical treatment showed the shortest survival after diagnosis.

In children, the multimodal treatment protocols for rhabdomyosarcoma are well-defined and led to an improved survival rate, especially in those with non-metastatic disease (16-18). In adults, however, the same protocols showed much less response $(19,20)$. Due to the rareness of the disease in adults, the use of a variety of chemotherapeutic agents in studies involving an adult patient collective and a standardized chemotherapy regime have yet to be established (19-22).

As it is known, in patients with malignant tumors, an elevated level of LDH can frequently be observed. This applies especially in advanced metastatic stages of the disease $(23,24)$. In the present case, the patient presented an elevated LDH level of $264 \mathrm{U} / 1$ prior to surgery. Similar to this case, Yeasmin et al. (7) presented a case of a patient with pure pleomorphic rhabdomyosarcoma of the uterus with elevated LDH level, where, furthermore, the degree of elevation showed a correlation to the progression of the disease. These findings are in line with the result of Nagai et al. (25) presenting significantly elevated LDH levels in patients with uterine sarcomas, whereby no patients with uterine rhabdomyosarcomas were in the investigated patient collective.
In comparison, Nelson et al. (26) found normal or near normal LDH isoenzyme patterns in patients with uterine sarcomas with rhabdomyosarcomatous differentiation.

All in all, due to the presence of an initial elevation of LDH level and lack of other prognostic markers, the fluctuation of the elevation may be used as tumor marker for further follow-ups and an early detection of possible recurrence of the disease. Based on this case report we initiated a register for gynecological sarcomas called REGSA.

\section{Conflicts of Interest}

None.

\section{References}

1 Chmaj-Wierzchowska K, Wierzchowski M, Szymanowski K, Czerniak T, Mróz M, Sobiak S and Opala T: Pleomorphic rhabdomyosarcoma of the uterine corpus-A case report. Ginekol Pol 81(7): 541-543, 2010.

2 Holcomb K, Francis M, Ruiz J, Abulafia O, Matthews RP and Lee YC: Pleomorphic rhabdomyosarcoma of the uterus in a postmenopausal woman with elevated serum CA125. Gynecol Oncol 74(3): 499-501, 1999.

3 Borka K, Patai K, Rendek A, Sobel G and Paulin F: Pleomorphic rhabdomyosarcoma of the uterus in a postmenopausal patient. Pathol Oncol Res 12(2): 102-104, 2006.

4 McCluggage WG, Lioe TF, McClelland HR and Lamki $\mathrm{H}$ : Rhabdomyosarcoma of the uterus: Report of two cases, including one of the spindle cell variant. Int J Gynecol Cancer 12(1): 128-132, 2002.

5 Fadare O, Bonvicino A, Martel M, Renshaw IL, Azodi M and Parkash V: Pleomorphic rhabdomyosarcoma of the uterine corpus: A clinicopathologic study of 4 cases and a review of the literature. Int J Gynecol Pathol 29(2): 122-134, 2010.

6 Ordi J, Stamatakos MD and Tavassoli FA: Pure pleomorphic rhabdomyosarcomas of the uterus. Int J Gynecol Pathol 16(4): 369-377, 1997.

7 Yeasmin S, Nakayama K, Oride A, Ishibashi M, Ishikawa N, Katagiri A, Iida K, Nakayama $\mathrm{N}$ and Miyazaki K: A case of extremely chemoresistant pure pleomorphic rhabdomyosarcoma of the uterus associated with high serum LDH level. Eur J Gynaecol Oncol 29(5): 518-522, 2008.

8 Leung F, Terzibachian JJ, Govyadovskiy A and Lassabe C: Postmenopausal pure rhabdomyosarcoma of the uterine corpus associated with previous pelvic irradiation. Arch Gynecol Obstet 279(2): 209-211, 2009.

9 Ferguson SE, Gerald W, Barakat RR, Chi DS and Soslow RA: Clinicopathologic features of rhabdomyosarcoma of gynecologic origin in adults. Am J Surg Pathol 31(3): 382-389, 2007.

10 Siegal GP, Taylor III LL, Nelson KG, Reddick RL, Frazelle M, Siegfried JM, Walton LA and Kaufman DG: Characterization of a pure heterolgous sarcoma of the uterus: Rhabdomyosarcoma of the corpus. Int J Gynecol Pathol 2(3): 303-315, 1983

11 Vakiani M, Mawad J and Talerman A: Heterologous sarcoma of the uterus. Int J Gynecol Pathol 1(2): 211-219, 1982. 
12 Podczaski E, Sees J, Kaminski P, Sorosky J, Larson JE, DeGeest $\mathrm{K}$, Zaino RJ and Mortel R: Rhabdomyosarcoma of the uterus in a postmenopausal patient. Gynaecol Oncol 37: 439-342, 1990.

13 Okada DH, Rowland JB and Petrovic LM: Uterine pleomorphic rhabdomyosarcoma in a patient receiving tamoxifen therapy. Gynecol Oncol 75: 509-513, 1999.

14 Jaworski R, Rencoret $\mathrm{R}$ and Moir D: Pleomorphic rhabdomyosarcoma of the uterus. Case report with review of the literature. Br J Obs Gynaecol 91(12): 1269-1273, 1984.

15. Chekerov R, Denkert C, Boehmer D, Suesse A, Widing A, Ruhmland B, Giese A, Mustea A, Lichtenegger W and Sehouli $\mathrm{J}$ : Online tumor conference in the clinical management of gynecological cancer: Experience from a pilot study in Germany. Int J Gynecol Cancer 18(1): 1-7, 2008.

16 Crist BW, Gehan EA, Ragab AH, Dickman PS, Donaldson SS, Fryer C, Hammond D, Hays DM, Herrmann J, Heyn R, Jones PM, Lawrence W, Newton W, Ortega J, Raney RB, Ruymann FB, Tefft M, Webber B, Wiener E, Wharam M, Vietti TJ and Maurer HM: The Third Intergroup Rhabdomyosarcoma Study. J Clin Oncol 13(3): 610-630, 1995.

17 Crist BWM, Anderson JR, Meza JL, Fryer C, Raney RB, Ruymann FB, Breneman J, Qualman SJ, Wiener E, Wharam M, Lobe T, Webber B, Maurer HM and Donaldson SS: Intergroup Rhabdomyosarcoma Study-IV: Results for patients with nonmetastatic disease. J Clin Oncol 19(12): 3091-3102, 2001.

18 Raney RB, Anderson JR, Barr FG, Donaldson SS, Pappo AS, Qualman SJ, Wiener ES, Maurer HM and Crist WM: Rhabdomyosarcoma and undifferentiated sarcoma in the first two decades of life: A selective review of intergroup rhabdomyosarcoma study group experience and rationale for intergroup Rhabdomyosarcoma Study V. J Pediatr Hematol Oncol 23(4): 215-220, 2001.

19 Ferrari A, Dileo P, Casanova M, Bertulli R, Meazza C, Gandola L, Navarria P, Collini P, Gronchi A, Olmi P, Fossati-Bellani F and Casali PG: Rhabdomyosarcoma in adults a retrospective analysis of 171 patients treated at a single institution. Cancer 98(3): 571-580, 2003.
20 Little DJ, Ballo MT, Zagars GK, Pisters PWT, Patel SR, El-Naggar AK, Garden AS and Benjamin RS: Adult rhabdomyosarcoma: outcome following multimodality treatment. Cancer 95(2): 377388, 2002.

21 Ogilvie CM, Crawford EA, Slotcavage RL, King JJ, Lackman RD, Hartner L and Staddon AP: Treatment of adult rhabdomyosarcoma. Am J Clin Oncol 33(2): 128-131, 2010.

22 Esnaola NF, Rubin BP, Baldini EH, Vasudevan N, Demetri GD, Fletcher CDM and Singer S: Response to chemotherapy and predictors of survival in adult rhabdomyosarcoma. Ann Surg 234(2): 215-223, 2001.

23 Hsieh $\mathrm{K}$ and Blumenthal $\mathrm{H}$ : Serum lactic dehydrogenase levels in various disease states. Proc Soc Exp Biol Med 91(4): 626$630,1956$.

24 Widy-Kierska K and Roszkowski I: LDH Isoenzymes in patients with uterine tumors. Obstet Gynecol 33(2): 173-176, 1969.

25 Nagai T, Takai Y, Akahori T, Ishida H, Hanaoka T, Uotani T, Sato S, Matsunaga S, Baba K and Seki H: Novel uterine sarcoma preoperative diagnosis score predicts the need for surgery in patients presenting with a uterine mass. Springerplus 3: 678, 2014.

26 Nelson KG, Siegfried JM, Siegal GP, Becker R, Walton LA and Kaufman DG: The heterogeneity of LDH isoenzyme patterns of human uterine sarcomas and cultured sarcoma cell lines. Am J Pathol 116(1): 85-93, 1984. 